\title{
CLIMATIC CHARACTERISTICS AND THE TEMPERATURE REGIME OF ASPHALT PAVEMENTS
}

Traffic density and climate are important external factors influencing pavement mechanics. Climatic conditions influence the service life of materials, damage to roads etc. In many countries the climatic characteristics are implemented into calculation systems for pavement construction. The importance of the implementation of climate characteristics into the calculation systems is increasing in the context of global climatic processes and changes, especially the changes in air temperature. The aim of the following paper is to highlight the changes of climatic characteristics used in highway engineering and their effect on the change of pavement thermal flow.

\section{Introduction}

Besides traffic density, climate is the second important external factor influencing pavement mechanics. There are several climatic characteristics, which must be taken into consideration, regarding pavement behaviour:

- air temperature

- minimum and maximum air temperature

- frost index

- sun radiation

- rainfall

- atmospheric moisture etc.

Air temperature changes during daily and yearly cycles develop the changes of strength and deformation characteristics of particular pavement layers as well as the changes in bearing capacity of the pavement subgrade. Air conditions also influence the service life of materials, damage to roads etc.

Therefore in many countries climatic characteristics are implemented into the calculation systems of pavement construction. The importance of the implementation of climate characteristics into the calculation systems is increasing in the context of global climatic processes and changes, especially the changes in air temperature. The aim of the following paper is to highlight the changes of climatic characteristics used in highway engineering and their effect on the change of pavement thermal flow.

The measurement of air temperatures in five characteristic localities of Slovakia between 1980 - 2001 were used to study the problem of climatic conditions. The temperature data was received from the Hydrometeorological Institute in Bratislava, and from experiments on air, road and pavement temperatures carried out by the authors [1, 2, 3, 4]. The presented problem is solved in the research projects num. 1/8194/01 and the project "The research of influence of climatic and traffic conditions on pavement mechan- ics", supported by the grant agency VEGA and by the Ministry of Education SR Bratislava [1].

\section{Results of air temperature measurements in Slovakia}

One climatic characteristic which must be measured in order to determine the thermal flow of the pavement is air temperature. Knowledge of air temperature and its characteristics is used in the design and evaluation of the pavements in practise. The analysis of thermal conditions in Slovakia with its characteristics was made on the basis of air temperature measurements made over 21 years from 1. 1. 1980 to 31. 12. 2001 in the following five characteristic localities in Slovakia:

1. Bratislava, south-western locality of Slovakia,

2. Žilina, north-western Slovakia

3. Hurbanovo, southern Slovakia

4. Poprad, northern and mountainous region of Slovakia,

5. Košice, eastern Slovakia east.

From the results obtained, the following climatic characteristics can be given:

- the yearly flow of average daily air temperatures $\left(T_{s}\right)$,

- the medium yearly air temperatures $\left(T_{m}\right)$,

- the characteristics of the winter period as the frost index $\left(I_{m}\right)$, number of days where ice is present, frosty periods, minimum air temperatures $\left(T_{\min }\right)$.

\subsection{Daily and yearly characteristics of air temperatures}

a) Average daily air temperature $\left(T_{s}\right)$

The air temperature changes cyclically achieving minimum and maximum values. The daily temperature flow is expressed by average daily air temperature $T_{s}$, that is defined in the next formula

\footnotetext{
* Ján Čorej, Martin Korenko, Eva Remišová

University of Žilina, Faculty of Civil Endineering, Department of Road Engineering, Komenského 52, 01026 Žilina, E-mail: corej@fstav.utc.sk
} 


$$
T_{s}=\frac{T_{7}+T_{14}+2 \cdot T_{21}}{4}
$$

where indexes 7, 14 and 21 are the times of air temperature measurement $T$ in ${ }^{\circ} \mathrm{C}$. This temperature is measured $2 \mathrm{~m}$ above ground level.

\section{b) Average yearly air temperature $T_{m}$}

The average yearly air temperature is another important characteristic of air conditions. It is the temperature defined as the ratio of the average daily air temperature summary during one year to the number of days in a year:

$$
T m=\frac{\sum_{i=1}^{365} T_{s}}{365}
$$

The evaluation example of the yearly flow of the average daily air temperatures between 1980 and 2001 in Žilina is shown in figure 1 .

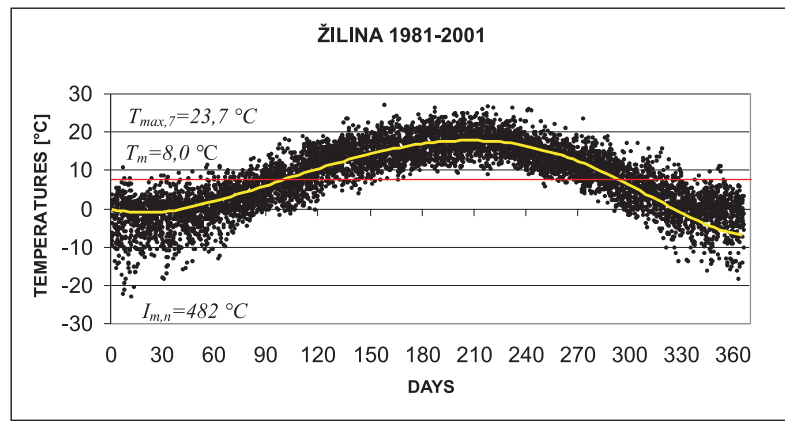

Fig. 1 Yearly flow of average daily air temperatures

The air temperatures at particular measuring stations in Slovakia were evaluated using the same method. The example of average yearly air temperature flows over 21 years in two characteristic regions of Slovakia - Žilina in the north of Slovakia and Bratislava in the south is presented in figure 2 .

One of the aims of this paper is to show the range of changes in thermal characteristics as a consequence of global changes. The differences in average yearly temperatures in particular years as well as an increase in average air temperatures are evident. The regression analysis of the trend of temperature changes over 21 years is shown in figure 3 . The time behaviour of air temperatures has an increasing character.

A review of the average yearly air temperatures $T_{m}$ which are statistically evaluated over the period of 21 years in five defined stations is presented in table 1. Data of average yearly temperatures in SR used according to the Map of the average yearly air temperatures [5] is shown. The average yearly temperature increases by about $1{ }^{\circ} \mathrm{C}$.

The next characteristics of a period of one year are the maximum and the minimum average daily air temperatures $T_{\max }$
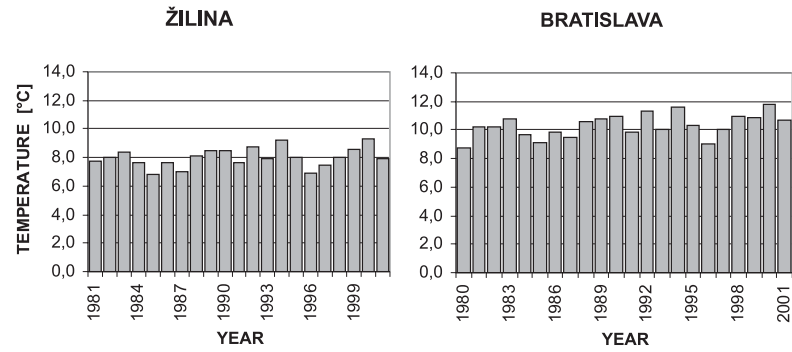

Fig. 2 Average yearly air temperatures in Žilina and in Bratislava during the period of $1980-2001$

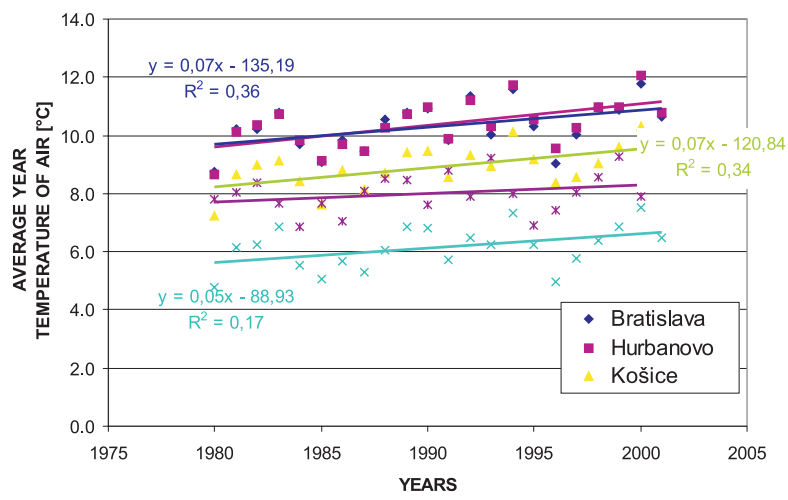

Fig. 3 Trends of the average yearly air temperatures

and $T_{\min }$. The statistics of $T_{\max }$ and $T_{\min }$ during 21 years are presented in table 1 .

The yearly characteristics of air temperatures

Table 1

\begin{tabular}{|c|c|c|c|c|}
\hline Region & Elevation & \multicolumn{3}{|c|}{ Thermal characteristics [in $\left.{ }^{\circ} \mathrm{C}\right]$} \\
\cline { 3 - 5 } & above sea level & $T_{m}$ & $T_{\max }$ & $T_{\min }$ \\
\hline Poprad & 695 & $6(5)$ & 22 & -16 \\
\hline Žilina & 365 & $8(7)$ & 24 & -15 \\
\hline Košice & 230 & $9(8)$ & 25 & -12 \\
\hline Bratislava & 131 & $10(9)$ & 27 & -10 \\
\hline Hurbanovo & 115 & $10(9)$ & 28 & -11 \\
\hline
\end{tabular}

\subsection{Characteristics of a summer period}

One of the important problems of asphalt pavements is their resistance to rutting during traffic in summer. The intensity of the Sun's radiation and air temperatures influence the input parameters of asphalt surfaces, such as resilient modulus, strength characteristics etc. The basic characteristics of the summer period that influence the mechanical behaviour of pavement layers are:

- the maximum summer air temperature,

- the thermal index.

a) Average maximum 7-day air temperature 
The air temperature is a variable factor that depends on a balance of thermal energy on the pavement surface. The maximum air temperatures are used to determine the border air temperatures (tab. 1). The temperatures, which have long-term effects, are important for the stabilization of the thermal field. One of the possibilities is an empirical determination of the maximum air temperatures during seven consecutive days with maximum air temperatures $T_{\max , 7}$. The average maximum 7-day air temperature in a year is determined as the ratio of the summary of temperatures over seven consecutive days to the number of days -7 days.

The standard value of maximum 7-day air temperature $T_{\text {air,max }}$ (in ${ }^{\circ} \mathrm{C}$ ) according to the program SHRP (Strategic Highway research program) [6] is statistically the value of the average yearly values from a long term monitoring (20 years):

$$
T_{\text {air, } \max }=\bar{T}_{\max , 7}+2 \sigma
$$

where $\bar{T}_{\max , 7}$ is the average 7-day air temperature during the monitoring period, in ${ }^{\circ} \mathrm{C}$,

$\sigma \quad$ is standard deviation.

The example of a search for a 7-day period in a year with maximum temperatures and flow of maximum air temperatures in the Bratislava region during the 21-year period is presented in figure 4 .

\section{b) Thermal index}

The thermal index $I_{t}$ is the characteristic which represents summer thermal conditions, especially asphalt pavement defects characteristic to the summer period. It is defined as the summary of the average daily air temperatures that are higher than $20^{\circ} \mathrm{C}$ in the summer period. For illustration results from the Bratislava and Žilina stations are shown in figure 5. It is evident that there is a significant difference between these two regions. The values in Bratislava are greater than the values in Žilina.
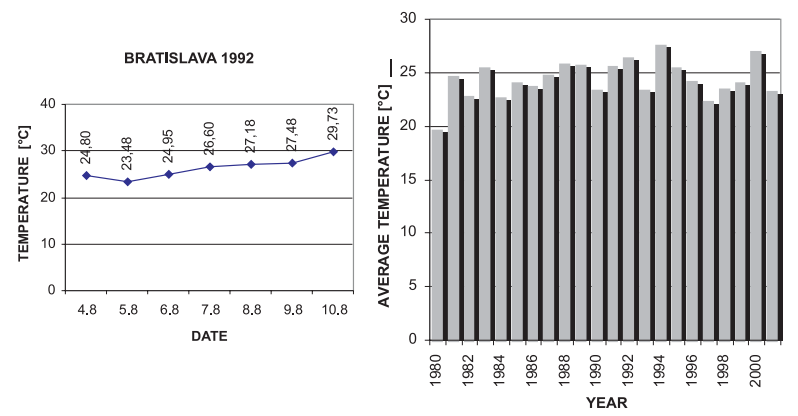

Fig. 4 Flow of the average 7-days' maximum temperatures

The summer period is characterised also by the number of summer days $n_{L}$ (those with temperatures above $20^{\circ} \mathrm{C}$ ) and the average summer temperature $T_{p, L}=\left(I_{t} / n_{L}\right)$. The summer period characteristics are in table 2.

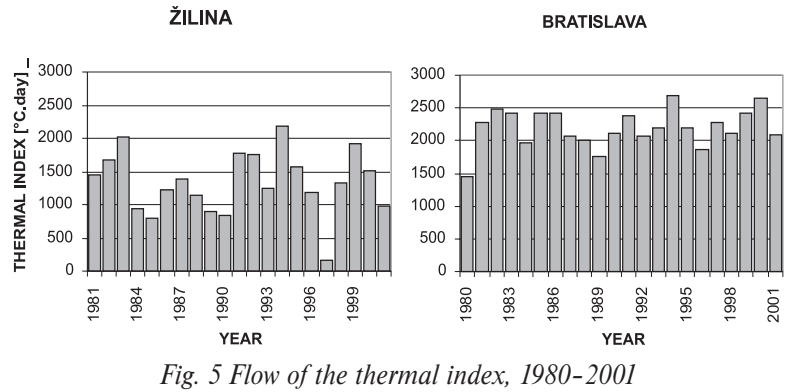

Monitoring characteristics of the summer period

Table 2

\begin{tabular}{|c|c|c|c|c|c|}
\hline Region & Elevation & \multicolumn{4}{|c|}{ Thermal characteristics [in $\left.{ }^{\circ} \mathrm{C}\right]$} \\
\cline { 3 - 6 } & above sea level & $n_{L}$ & $T_{p, L}$ & $I_{t}$ & $T_{\text {airmax }}$ \\
\hline Poprad & 695 & 47 & 16,0 & 767 & 22 \\
\hline Žilina & 365 & 76 & 17,5 & 1332 & 24 \\
\hline Košice & 230 & 102 & 18,7 & 1941 & 26 \\
\hline Bratislava & 131 & 112 & 19,6 & 2195 & 28 \\
\hline Hurbanovo & 115 & 123 & 19,5 & 2384 & 27 \\
\hline
\end{tabular}

\subsection{Characteristics of a winter period}

The most important characteristic of a winter period from a highway engineering point of view is frost index $I_{m}$ (in ${ }^{\circ} \mathrm{C}$ ) It is the characteristic which expresses the intensity and the duration of a frost period. According to [5] the frost index is defined as the maximum negative value of a summary of the average daily air temperatures $T_{s}$ in a winter period:

$$
I_{m}=\sum_{t_{z}}^{t_{k}} T_{s}
$$

where $t_{z}$ is the beginning of a winter period,

$$
t_{k} \text { is the end of a winter period. }
$$

The flow of the frost indexes during the years 1980 - 2001 in the Bratislava region and Žilina region is shown in figure 6.
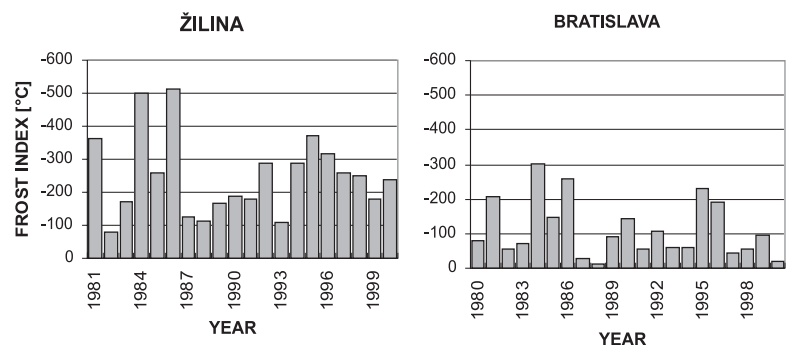

Fig. 6 The Frost index values for a period of twenty years

The frost index values are changed from a minimum value of $20{ }^{\circ} \mathrm{C}$ in Hurbanovo in winter $2000 / 01$ up to a value of $742{ }^{\circ} \mathrm{C}$ in Poprad in winter $1986 / 87$. For practical purposes the design value 
of the frost indexes $I m, n$ determined statistically from a long-term monitoring is used. The statistics of the frost indexes during the 21-year period and the values according to the Map of designed frost indexes STN 736114 [5] are in table 3.

The main characteristics of winter period

Table 3

\begin{tabular}{|c|c|c|c|}
\hline Region & \multirow{2}{*}{$\begin{array}{c}\text { Elevation } \\
\text { above sea level }\end{array}$} & \multicolumn{2}{|c|}{ Thermal characteristics [in ${ }^{\circ} \mathrm{C}$ ] } \\
\cline { 3 - 4 } & 695 & $73, n$ & $\operatorname{Im}, n[$ STN 73 6114] \\
\hline Poprad & 365 & 482 & 700 \\
\hline Žilina & 230 & 473 & 475 \\
\hline Košice & 131 & 272 & 350 \\
\hline Bratislava & 115 & 272 & 300 \\
\hline Hurbanovo & &
\end{tabular}

The design values of frost indexes decrease; the winter periods are warmer.

\section{Thermal flow of the pavement}

The research into the effect of thermal conditions on pavement thermal flow was realised by using "Experimental stand of pavement mechanic" built in the authors' place of work. The stand consists of two testing pavements with a system of scanning and registration of temperatures [7]. The constructions of pavements with the position of thermometers are shown in figure 7 . The testing pavements are different in type and in the thickness of their base layers.

In the research into the thermal flow of pavements results were used which had been measured and registered continually since 2002. The characteristic air temperature flow, as well as the tem-

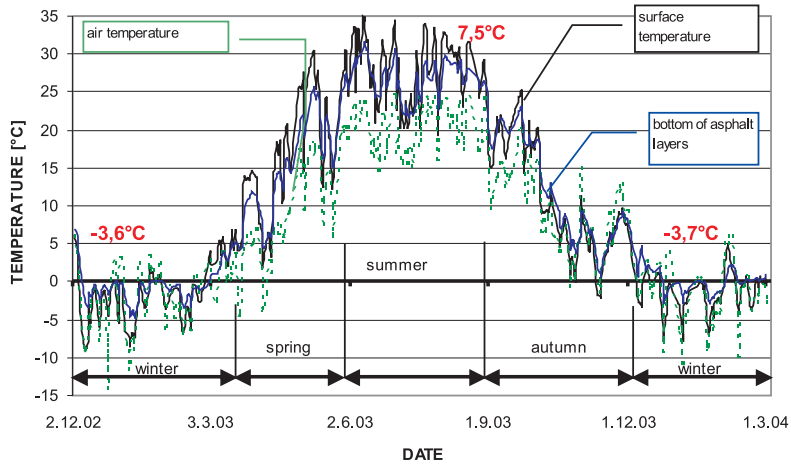

Fig. 8 Air temperature flow and pavement temperature flow for the period of $2003-2004$

perature flow at the surface and bottom of the asphalt layers, is presented in figure 8 .

\subsection{Research into the relationship between the air temperature and the pavement surface temperature}

One of the important characteristics of pavement thermal flow is the temperature of the pavement surface. The pavement surface is the most loaded part. The theoretical deduction of the mathematical relation of pavement surface temperature goes out the thermal balance at surface [5]. According to SHRP it is possible to determine the maximum temperature of the asphalt pavement surface $T_{\max , p}$ in the summer period at a depth of $20 \mathrm{~mm}$ and the minimum temperature of the asphalt pavement surface $T^{\min }$ in the winter period

$$
\begin{aligned}
T_{\text {max }, p} & =\left(T_{\text {air,max }}-0,00618 . L A T^{2}+0,2289 . L A T+\right. \\
& +42,2) \cdot 0,9545-17,78 \\
T_{\text {min }, p} & =T_{\text {air,min }}
\end{aligned}
$$
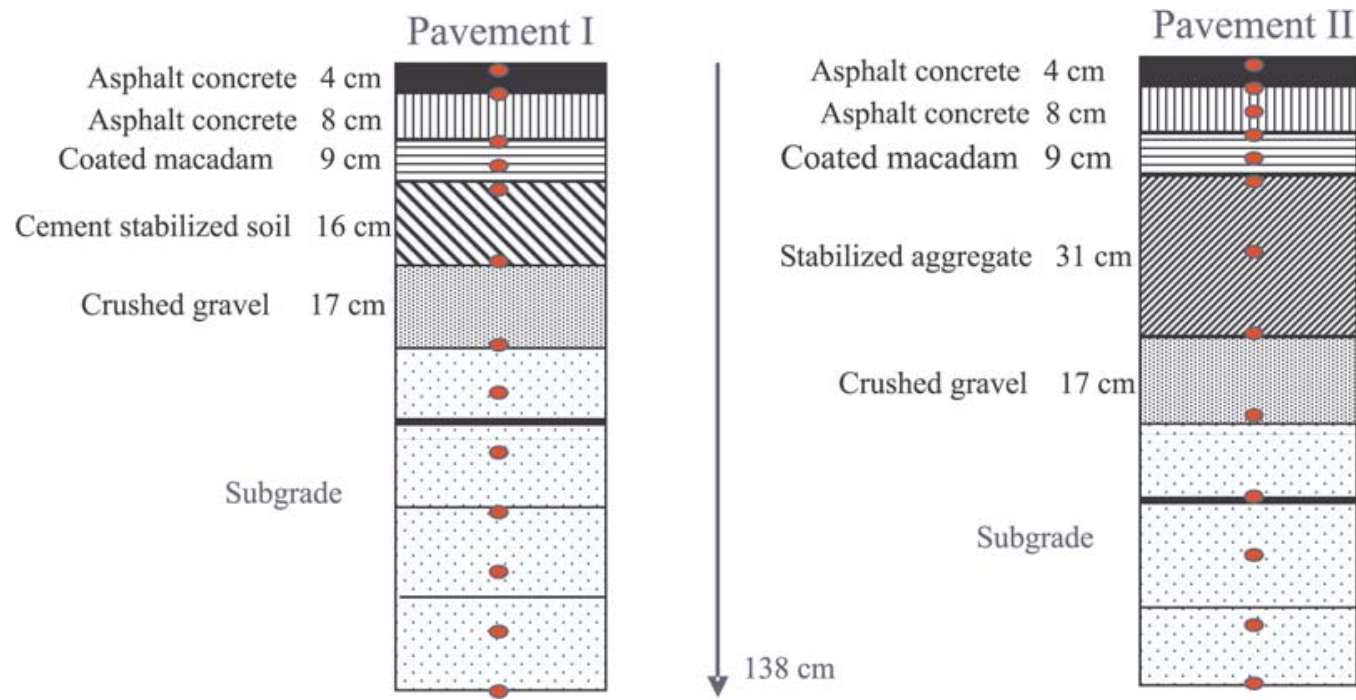

Fig. 7 Pavements' construction of the experimental stand 
where $T_{\max , p}$ is the maximum design temperature of the asphalt pavement surface to a depth of $20 \mathrm{~mm}$ with $98 \%$ reliability in $\left[{ }^{\circ} \mathrm{C}\right]$

$T_{\text {min, }}$ is the minimum design temperature of the asphalt surface, in $\left[{ }^{\circ} \mathrm{C}\right]$

$T_{\text {air,max }}$ is the maximum design air temperature, according to $(3)$, in $\left[{ }^{\circ} \mathrm{C}\right]$

$T_{\text {air,min }}$ is the minimum design air temperature, in $\left[{ }^{\circ} \mathrm{C}\right]$

LAT is the geographic latitude of the monitoring locality.

The design temperatures of asphalt pavements in five localities of Slovakia are as follows:
- in Žilina
$41,9{ }^{\circ} \mathrm{C}$
- in Poprad
$40,0^{\circ} \mathrm{C}$
- in Košice
$44,1^{\circ} \mathrm{C}$
- in Hurbanovo
$45,3{ }^{\circ} \mathrm{C}$
- in Bratislava
$46,1^{\circ} \mathrm{C}$.

The utilisation of these equations in Slovak conditions was studied at the experimental stand in Žilina. The relation between the air temperature and the pavement surface temperature (temperatures measured during the summer period of 2003) is presented in figure 9.

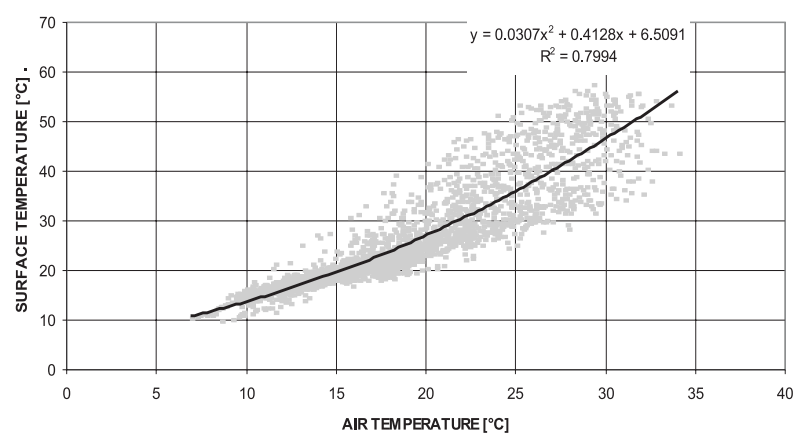

Fig. 9 Relation between the pavement temperature and the air temperature; in the period of 22.5. - 5.9. 2003

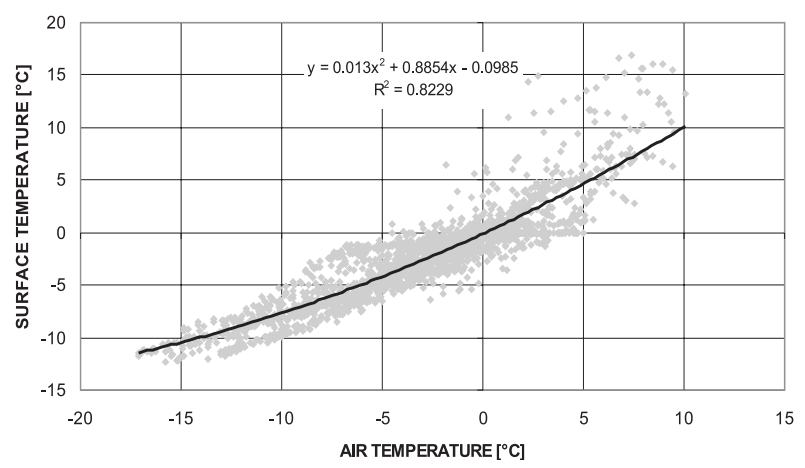

Fig. 10 Relation between the pavement temperature and air temperature; during the period of 2. 12. 2002 - 4. 3. 2003
The pavement surface temperature is about $36{ }^{\circ} \mathrm{C}$, according to figure 9, at an air temperature of $25^{\circ} \mathrm{C}$ in Žilina. However, the result does not correspond with the temperature $41,9^{\circ} \mathrm{C}$ determined according to SHRP. The relation between the air temperature and the pavement surface temperature in the winter period of 2002/ 2003 is presented in figure 10 . The measurement of this relation in the winter period shows a narrower spread of results.

The following research characteristic is the yearly range of temperatures in particular layers in respect of the thermal loading. Figure 11 shows the temperature distribution in a one year cycle, $2003 / 04$, the thermal range of "a hot summer day" (green line), "a cold summer day" (blue line) and "the coldest winter day" (red line). It is quite evident that the wearing course is thermally the most loaded layer (approximately $65{ }^{\circ} \mathrm{C}$ in summer), the temperature on the subgrade changes within a range of $25^{\circ} \mathrm{C}$ and about $16{ }^{\circ} \mathrm{C}$ at a depth of $140 \mathrm{~cm}$.

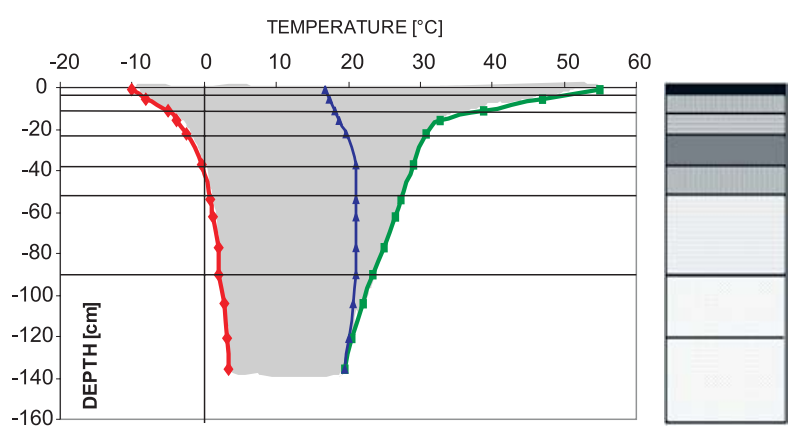

Fig. 11 One year temperatures range in pavement I

Another important characteristic is the temperature of the asphalt layers in terms of evaluating pavement behaviour (fig. 12).
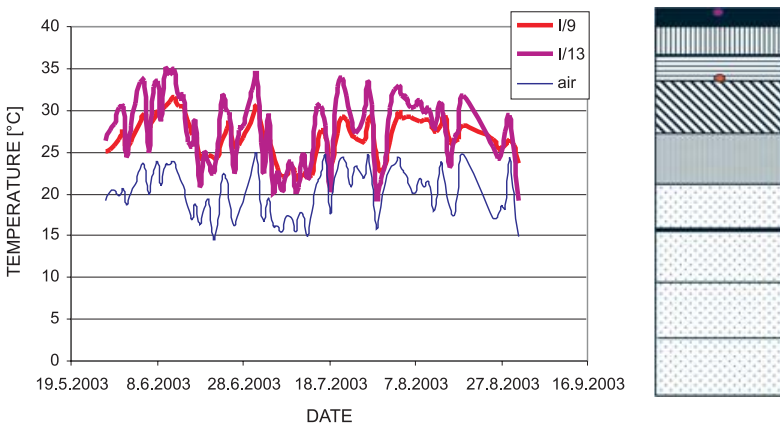

Fig. 12 Temperatures on the pavement surface and in the bottom level of asphalt layers

\section{Conclusions}

The presented paper analyses two important problems with respect to pavement design methods: 
1. the trend of changes in climatic characteristics used in highway engineering following global climatic changes and then

2. the results of these changes on pavement thermal flow.

Although the monitoring period of 21 years is not sufficient to present a complete summary, it is quite possible to put forward some conclusions that could be applied in practice. One of them is the requirement for continued monitoring of, and research into, the problem. The thermal effects influence markedly the thermal flow and thereby the pavement degradation. The following important facts were observed at five monitoring stations in Slovakia during the period of 21 years:

- the increase of the average yearly temperature $T_{m}$ by about $1{ }^{\circ} \mathrm{C}$
- the increase of 7-day air temperatures and the thermal indexes,

- and slow regress of the intensity of the winter period.

The measured results of the influence of climatic effects on pavement thermal flow showed a clear relationship between the air temperature and the pavement surface temperature. These results allow detailed analyses of the temperature of particular pavement layers and research their effect on the mechanics of different layers. An important result is also the knowledge that the method of the pavement thermal flow measurement at the experimental stand proved to be useful and it also helps the investigation of important thermal characteristics of road pavements.

\section{References}

[1] ČOREJ, J. AND COL.: The research of influence of climatic and traffic conditions on pavement mechanics, Grant projects VEGA, 2004.

[2] ČOREJ, J., REMIŠOVÁ, E.: Analysis of climatic conditions from the road pavement mechanics point of view. Science, Education and Society. 11. International Scientific Conference, section 1, Žilina, 17. - 19. 9. 2003, ISBN 80-8070-116-4.

[3] ČOREJ, J., KORENKO, M., ŠEDIVÝ, T.: The characteristics of summer period and pavement thermal flow, Proceedings from VIII, Conference Dialnica, 6.-7.11.2003, Bratislava 2003.

[4] BANDŽÁKOVÁ, M.: The monitoring and evaluation of climatic characteristics and pavement thermal flow, diploma work, April 2003.

[5] STN 73 6114: Highway pavements, Basic setting, 1997.

[6] BLAB, R.: Analytische Methoden zur Modellierung der Verformungseigenschaften flexibler Fahrbahnaufbauten, 11 Mitteilungen, ISTU Wien 2001.

[7] ČOREJ, J., ČELKO, J., TROJANOVÁ, M.: Water and thermal flow of baulk subgrade, ES VŠDS Žilina 1994, ISBN 80-7100-174-0. 